\title{
Minireview
}

\section{Cell Cycle Exit: Growth Arrest, Apoptosis, and Tumor Suppression Revisited}

\author{
Lennart Philipson \\ Skirball Institute of Biomolecular Medicine, New York University \\ Medical Center, New York, New York, U.S.A.
}

Studies on regulation of cell growth have mainly focused on the growth induction machinery and only recently have they dealt with the complex pathways involved in cell cycle exit. One of the reasons for this one-sided focus may have been the overriding interest in cancer research and tumor induction, with the hope of unraveling new growth induction mechanisms. In retrospect, however, the majority of the cells in animals, including those in humans, are growth arrested and do not divide. Cell turnover may be controlled by apoptosis, but the reversible or irreversible growth arrest of differentiated cells is almost complete in the nervous system and mitosis signals are rare in most other tissues and organs. The molecular machinery controlling the arrested stage may therefore be even more complex than the growth induction mechanisms. In accordance with this hypothesis is the observation that the few bacteria capable of reversible growth arrest, such as the spores in B. subtilis, govern the spore-forming events by at least 30 genes in its relatively small genome. A defect in any one of these genes leads to a defective pathway, with lower survival under stressed conditions. Likewise, defects in cell cycle exit mechanisms in mammalian cells may cause severe diseases. The best examples come from the growing cadre of so-called tumor suppressor genes, which obviously belong to a category of genes governing and policing the arrested stage. In this minireview I will attempt to identify recent

Address correspondence and reprint requests to: Dr. Lennart Philipson, Skirball Institute of Biomolecular Medicine, New York University Medical Center, 540 First Avenue, New York, NY 10016, U.S.A. Phone: 212-263-8950; Fax: 212-263-8951; E-mail: philipso@saturn.med.nyu.edu progress in unraveling the control mechanisms involved in cell cycle exit and point to the diseases that might be associated with defective steps in these events.

\section{Arrest at the Transcriptional Level}

Every tissue appears to contain a cell type-specific configuration, allowing only genes relevant to that cell type to be transcribed. This noise reduction mechanism reduces the complexity of the substrate DNA available for the transcription machinery. On the other hand, when the chromatin has been opened, several specific activators and repressors may recognize the individual gene and its promoter in order to establish controlled expression of a desirable product. Therefore, in all eukaryotic cells we would expect at least a two-tiered level of transcriptional control-one at the chromatin level and one at the level of the opened genes.

\section{Chromatin Silencing}

Although it has been argued that chromatin silencing may limit genetic complexity (1), little is known about conserved mechanisms. In the yeast systems, on the other hand, both genes close to the telomere and those controlling mating type are regulated by silencing (2). In these cases, it appears that both acetylation and deacetylation of proteins are involved. Silencing should probably encompass three distinct processes: (i) establishment of a switch from active to silenced chromatin, (ii) maintenance of chromatin in the inactive state, and, most important, (iii) control of inheritance of the inactive state 
A

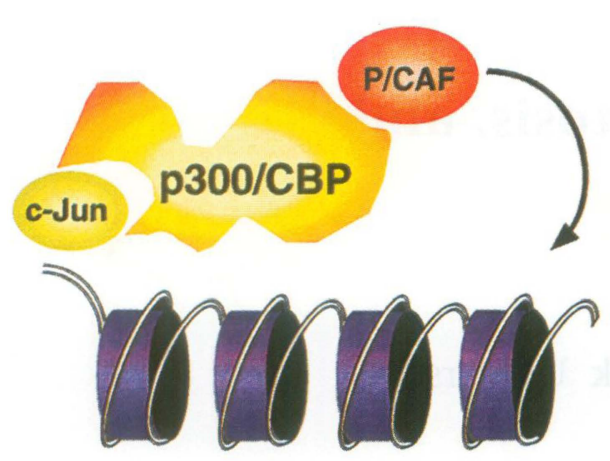

Acetylation of Histones
B

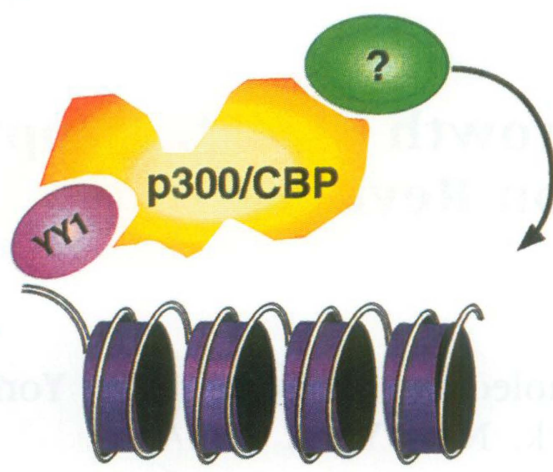

Deacetylation of
Fig. 1. Model of molecular functions involving histone acetylases and deacetylases. p300/CBP can be recruited to promoter elements by interaction with various sequencespecific transcriptional activators or repressors. P/CAF could also be recruited onto the specific promoters through interaction with p300/CBP, then acetylate (A) or deacetylate (B) histones in a promoterspecific manner. Targeted histone acetylation or deacetylation could contribute to promoter activation or repression by changing the chromatin structure. [Remodeled with permission from Yang et al., $1996^{7}$.] during chromatin replication (3). It appears that different genes are involved in the two wellcharacterized silencing phenomena, the mating type and the telomere in yeast.

Some insight has recently been offered by two yeast genes called something about silencing $(S A S)$ (4). Both genes seem to share sequences with known acetyltransferases from bacteria, Tetrahymena, and human cells. The human homologues include the HIV Tat-interacting protein 60 (TIP60) and MOZ, a gene fused to a transcriptional activator (CBP) in a subclass of acute myeloid leukemia patients characterized by the $t(8,16)$ (pl1;pl3) translocation (5). The CBP moiety has previously been identified as a transcriptional activator that can bind the CREB transcription factor (cyclic AMP element binding) upon stimulation with CAMP, but it can also work as a coactivator for retinoic acid receptors. Another similar coactivator, or adaptor, as they have often been called (6), namely p300, is very similar to CBP in mammalian cells. A domain has been identified in these proteins that is homologous to two yeast genes associated with chromatin that can bind histone acetylase activity. Likewise, both p300 and CBP can associate with $\mathrm{P} / \mathrm{CAF}$, which carries histone acetylase activity, in human cells (7). Thus, in both yeast and mammalian cells, histone acetylase can bind to proteins that recognize specific loci through associated transcriptional factors, leading to transactivation and histone acetylation. These adaptors can obviously bind not only to several transcription factors, such as CREB and Jun, but also to enzymes leading to opening of the chromatin through histone acetylation. Whether the acetylation causes transcriptional repression or activation depends on the transcription factors associated with the CBP or p300 and their DNA binding domain. Figure 1 shows schematically how p300/CBP can both activate or repress transcription depending on the factor associated with the adaptor. It is of considerable interest that defects in this system, as shown in Figure 2, can be involved in tumorigenesis. Direct mutations in CBP are associated with a heritable developmental disorder involving increased incidence of some tumors, the Rubinstein-Taybi syndrome (8). In other instances, a fusion protein made between a silencing acetylase (MOZ) and CBP leads to a specific class of acute myeloid leukemia. This may be caused by either a different specificity for the natural (P/CAF) and the fused acetylase or an irreversible acetylation function due to the tethered molecules. Proof of the reversibility of acetylase binding comes from the fact that viral oncogenes, such as ElA, can displace P/CAF from the CBP (7).

A true silencing function in mammalian cells has recently been revealed during studies of the $m y c$ oncogene and its homologues in cell culture. The Myc proteins, for which humans carry at least three genes, are able to form sequencespecific heterodimers with the Max protein, which leads to transcriptional activation, cell proliferation, and blocking of terminal differentiation. A translocation between an immunoglobulin gene and a myc gene in Epstein-Barr virus (EBV)-induced lymphomas provided clues to the importance of the $m y c$ oncogene in tumor induction (9). More recently, a gene (MNT) was identified that causes feedback inhibition of the 


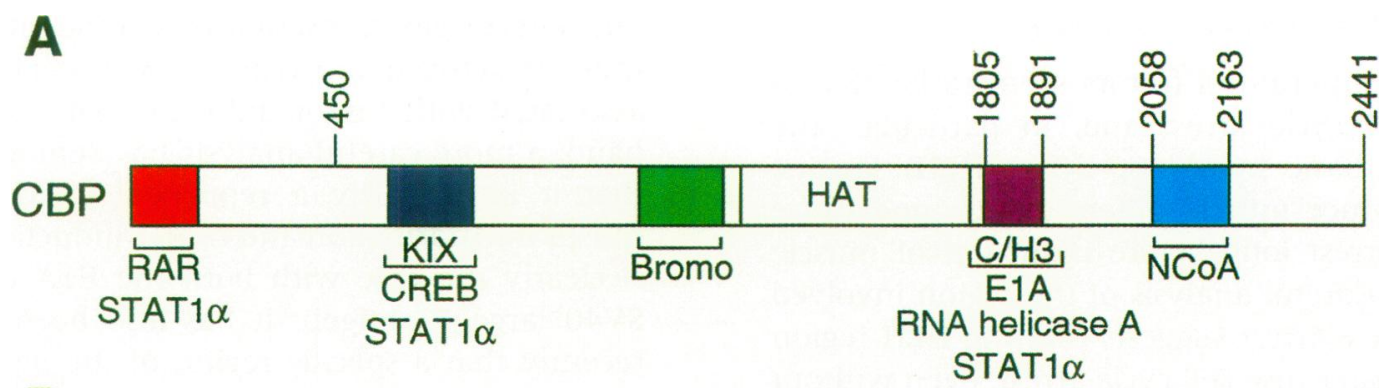

B

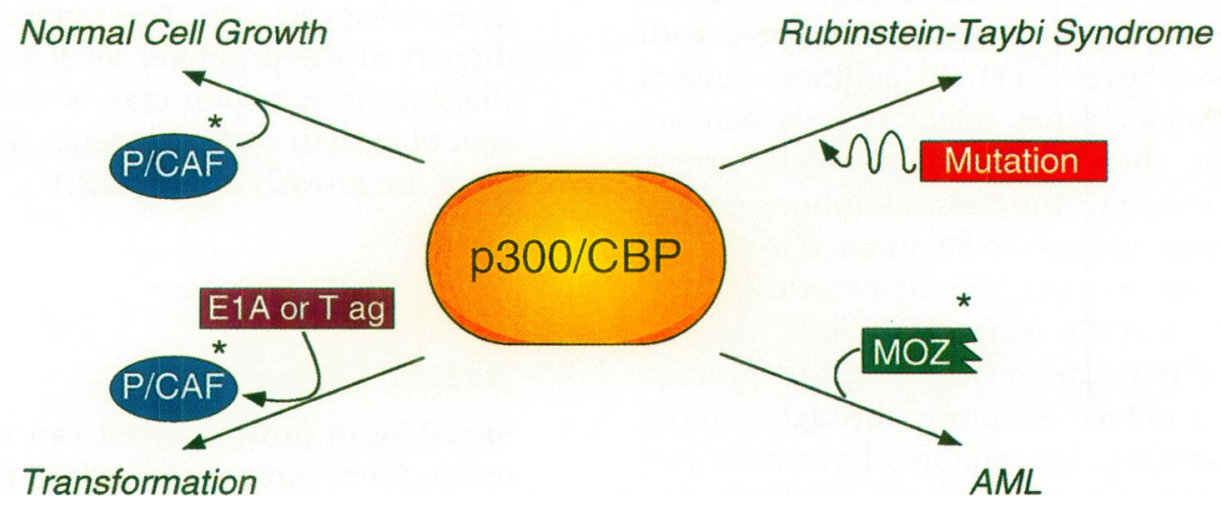

Fig. 2. Defects in p300/CBP activation or repression of transcription that result in tumorigenesis. (A) CBP interaction domains. The KIX (kinase-inducible interaction) domain mediates interactions with phosphorylated CREB and STATI $\alpha$. $\mathrm{C} / \mathrm{H} 3$ is a cysteine-histidine-rich region that mediates interactions with several factors, including ElA, STATl $\alpha$ and complex of RNA helicase A and RNA polymerase II. The region in CBP that interacts with nuclear receptor coactivators is indicated as NCoA. Numbers above CBP indicate endpoints of CBP deletion mutants. [Redrawn from Kurokawa et al., $1998^{36}$.] (B) CBP misfunction and cancer. The transcriptional coactivator CBP responds to numerous signals in regulating normal cell growth and devel-

transcriptional activation by Myc, competing out the Myc from the Max-Myc heterodimers (10). More interesting for chromatin silencing is the fact that mammals have another set of genes, the $M A D$ genes, that can also form heterodimers with Max, leading to silencing instead of activation (11). The Mad proteins all have a domain that can bind to so-called paired amphipathic helix (PAH) motifs in other proteins. Recently, it was demonstrated that $\mathrm{Mad}$ repression involved binding of two different proteins-one containing the PAH domains and the other histone deacetylase activity. The gene coding for the enzymatic activity is again the mammalian homologue to similar genes in yeast (11). Mad repression is obviously dependent on interaction with both of these proteins, which is probably caused by a condensation of the chromatin through opment. Abrogation of CBP functions is linked to at least three oncogenic events. CBP normally associates with the histone acetyltransferase P/CAF. Displacement of P/CAF occurs upon ElA and SV40 T antigen binding to CBP and this displacement contributes to cellular transformation. Fusion of CBP to translocated MOZ sequences is associated with specific subtypes of acute myeloid leukemias, and mutation of CBP leads to development of Rubinstein-Taybi syndrome. Substitution or loss of acetyltransferase activities $\left(^{*}\right)$ are now known to be involved in two of these three instances of CBP-related oncogenesis. [Adapted with permission from Roth, $1996^{37}$.]

deacylation of histones. Although we lack a molecular dissection of all the genes that respond to the myc system and its repressor functions, this complex system appears to be controlled at several levels.

That both acetylating and deacetylating events are involved in silencing is supported by the fact that some of the proteins interacting with p300/CBP can bind both enzymatic activities, depending on whether repression or activation is required. Thus, the deacetylase activity can function as co-repressor of the YYl transcription factor (12), whereas $\mathrm{P}(\mathrm{CAF})$ appears to be mostly activating. In conclusion, the chromatin structure-mediated activation and silencing involves several proteins in a complex interaction. Some of the components, if mutated or translocated, may be involved in tumorigenesis. 


\section{Promoter Control of Cell Cycle Exit}

Several transcription factors seem to be able to cause cell cycle arrest and, in particular, the group of basic helix-loop-helix (HLH) factors, which induce muscle differentiation and cause growth arrest long before induction of muscle proteins. Careful analysis of the region involved in cell cycle arrest suggests that the HLH region by itself can cause cell cycle arrest, even without the basic region (13). Other transcription factors, such as the $M A D$ genes, seem to compete with myc to impose arrest (11). In addition, several tumor suppressor genes might directly activate transcription, thereby inducing growth arrest, such as the $p 53$ gene, the classical tumor suppressor gene, which appears to be mutated in $50 \%$ of all human tumors (14). $p 53$ activates transcription of $p 21$, a cyclin kinase inhibitor, thereby arresting the cells late in Gl before the $S$ phase. p53 can also induce apoptosis through a more elaborate pathway, but mutants have been isolated that can cause growth arrest without subsequent apoptosis (15). In fact, in a few cases, $p 53$ controls growth arrest induced by a membrane protein without the participation of the transcription activation domain (16), which suggests that $p 53$ can interact with other molecules inside the cell remote from the transcription machinery.

Recently it has been established that the $p 53$ gene might need additional factors for maximum stimulation of growth arrest or induction of $p 21$, like the $p 33^{I N G}$ gene (17), which appears to bind to $p 53$ to achieve optimal effects. Among the Myc-interacting proteins, a new gene called $B I N 1$ has recently been isolated (18), which is highly expressed in skeletal muscle and is upregulated during myogenic differentiation. The pathway by which these cell cycle exit genes exert their effects is not clear, but those that have a transcription-activating function seem to affect other growth-inhibitory genes and their expression, including both the retinoblastoma $(\mathrm{Rb})$ protein and the cyclin-dependent kinase inhibitors. A possible route to identification of additional transcriptional factors that have growth arrest activities is exemplified by the recent isolation of the APM-1 gene (19), which obviously resides at the site for preferential insertion of one of the papilloma virus oncogenes in a cervical carcinoma cell line. This transcription factor encodes a zinc-finger protein with strong growth inhibitory activity. Many of the viral oncogenes, such as E1A, SV40 large T antigen, and $m y c$, exhibit a dual effect upon transcription. On the one hand, they can activate transcription, which earlier was associated with tumor induction. On the other hand, a more careful analysis has demonstrated that it is primarily a repressor function that causes transformation and tumor induction. This is clearly the case with both the ElA and the SV40 large $T$ antigen; it has also been shown recently that a specific region of the myc oncogene can repress transcription of a growth arrest gene called gas 1 (20). This repressor function acts directly at the promoter level and demonstrates that tumor induction may be due to the repression of growth cycle exit genes removing the cell from the growth arrest pool.

\section{Arrest Signaling}

Signaling of growth arrest can occur at several levels. Since most of the cells in the body remain arrested and are rarely induced to grow, there must be a complex growth arrest maintenance function. Once growth induction has occurred, a requirement for checkpoints for DNA damage and entry into the $\mathrm{S}$ phase immediately arises, and the mechanisms for checkpoint arrest might differ from those for the maintenance control. Likewise, early in embryogenesis the cells multiply freely and signaling for specific differentiation might occur, leading in most cases to arrest before the differentiation is executed. Finally, almost all cells in the body must turn over at a fixed rate, and the process of cell killing is advantageous during embryogenesis to eliminate some cells before a differentiation lineage can be established. This cell killing can occur both at the maintenance stage and at the checkpoints and seems to be governed at the transcriptional, signaling level as well as at the receptor-ligand level. Last but not least, several cells in the body require reversible growth arrest so that renewal of cells, although slow, can occur at regular intervals. Some cells, on the other hand, have reached an irreversible state of differentiation. When this happens, a stem-cell population must be available to induce the differentiation pathway when required. Some of the more recent findings on these phenomena partially mediated at the signal transduction level are discussed below. It appears that we need to differentiate between checkpoint arrest, apoptosis, and arrest at the quiescent state (probably G0) when discussing these molecular events. 


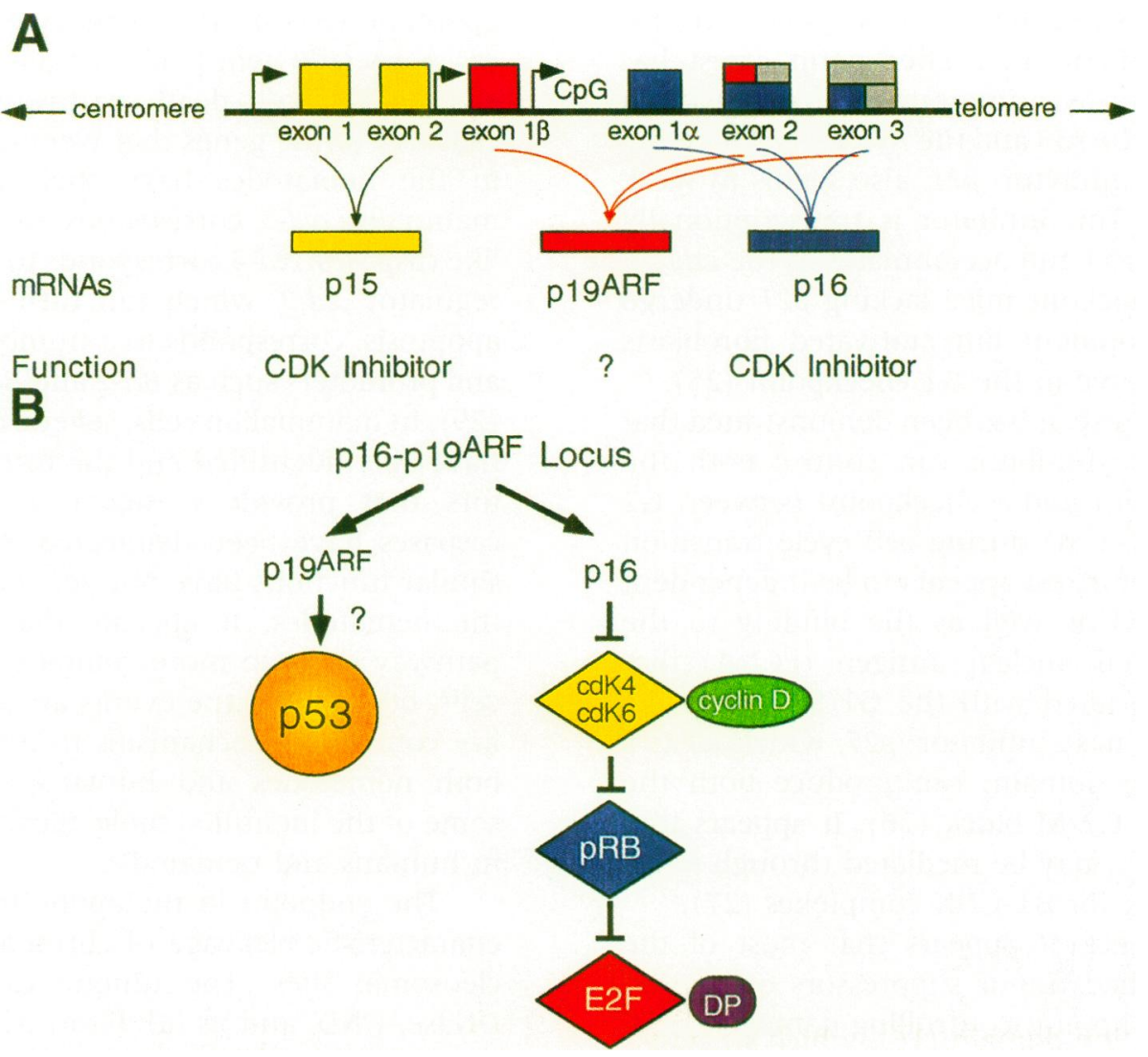

Fig. 3. (A) Genomic structure of the p16p19 ${ }^{A R F}$ locus. Blue boxes denote open reading frame 1 (ORF l) constituting the pl 6 transcript, red boxes indicate ORF 2 comprising the $p 19^{A R F}$ mRNA, and yellow boxes represent p15 exons. The presumptive promoters for the three transcripts are marked by arrows. For simplicity, the locus is not drawn to scale; genomic analysis of the human locus containing $p 16$ and $p 19^{A R F}$ indicates that it is approximately $30 \mathrm{~kb}$ and that exons $1 \beta$ and $1 \alpha$ are separated by $\sim 20 \mathrm{~kb}$. (B) Schematic representation of $p 16$ and postulated $p 19^{A R F}$ pathways. The $p 16$

\section{Checkpoint Arrest}

The two most frequently inactivated tumor suppressor genes in human cancer, irrespective of tumor type, site, and patient age, appear to be $p 53$ and INK4a $(21,22)$. The INK4 locus encodes pl6, which is a specific inhibitor of the cyclin D-dependent kinases CDK4 and CDK6 (23). This inhibitor prevents the kinases from phosphorylating the $\mathrm{Rb}$ proteins, in turn leading to a block in the Gl phase and no exit into the $S$ phase. Genetic disruption of this pathway is common in cancer cells and could be brought about either through inactivation of the tumor suppressors pl6 and $\mathrm{Rb}$ or by uncontrolled overex- pathway is simplified in this diagram. However, alterations in pl6, CDK4, cyclin D, and pRB appear to be mutually exclusive within an individual cell, suggesting that they have functionally equivalent consequences. The inability of $p 19^{A R F}$ to induce cell cycle arrest in cells lacking $p 53$ suggests a functional pathway, although the inactivation of $p 53$ in some tumors derived from $p 19^{A R F}$-null mice indicates that inactivation of these two genes is not functionally equivalent. The locus containing pl 6 and $p 19^{A R F}$ has also been called the $I N K 4 a-A R F$ locus. [Adapted with permission from Haber, $1997^{38}$.]

pression of the cyclins and their kinases. If the $p 53$ is concurrently inactivated, some cells are prevented from arresting in the Gl phase following DNA damage, which ultimately leads to a decrease in genomic stability and a block in the apoptosis pathway. As recently shown, the INK4 locus encodes three genes: $p 15$ and $p 16$, both of which are cyclin-kinase inhibitors, and in an alternative reading frame, $p 19$ [Fig. 3 (24)]. The latter probably acts upstream of the $\mathrm{Rb}$ and $p 53$, since fibroblasts from the knockout mice cannot exit the cell cycle or senesce. $p 19$ is therefore probably dependent on an intact $p 53$. The $p 19$ does not appear to carry a kinase-inhibitor activ- 
ity. The suggestion that all these genes are important ingredients in a checkpoint arrest has been borne out by numerous experiments with knockouts in the $p 53$ and the INK4 loci. Likewise, another CDK inhibitor, $p 21$, also seems to work at this stage. This inhibitor is transcriptionally controlled by $p 53$ and accumulates at the checkpoint. The knockout mice lacking $p 21$ undergo normal development but cultivated fibroblasts are only defective in the Gl checkpoint (25).

More recently, it has been demonstrated that the $p 21$ kinase inhibitor can control both the G1/S checkpoint and a checkpoint between G2 and mitosis (G2/M) during cell cycle transition (26). The latter arrest appears to be independent of $\mathrm{Rb}$ and $p 53$ as well as the binding to the proliferating-cell nuclear antigen (PCNA) that has been associated with the Gl/S checkpoint. Yet another kinase inhibitor, $p 27$, which lacks a PCNA binding domain, can produce both the G1/S and the G2/M block (26). It appears that this checkpoint may be mediated through binding to cyclin A- or B1-CDK complexes (27).

In retrospect, it appears that most of the isolated so-called tumor suppressors operate at the Gl/S checkpoint, controlling damaged DNA or stability of the genome before the cells enter into the $S$ phase. Another checkpoint at the $\mathrm{G} 2 / \mathrm{M}$ border was only recently identified.

\section{Apoptosis}

Programmed cell death, a term originally coined already in 1842, was rediscovered in the second half of this century and referred to as apoptosis in 1972. There are three major findings that have led to the conclusion that cell death is an active process under genetic control. First studies with a small nematode identified a number of genes regulating apoptosis (reviewed in ref. 28). Many of them have mammalian homologues that regulate cell death. The signal transduction pathway of apoptosis has identified specific death-signaling molecules, including a completely new family of cysteine proteases, the caspases. Many diseases in humans appear to be due to deficient regulation of the apoptotic program, and in mammalian cells there is a family of receptors, ligands, and signaling molecules that mediate apoptosis in specific cells. In the nematode, essentially three genes, ced-3, ced-4, and ced-9, are directly involved in executing apoptosis during development. Several other genes that also affect apoptotic death are required for recognition of apoptotic cells by the phagocytes, and in some cases, specific genes such as ces- 1 and ces- 2 can activate the cell death pathway in individual cells. All of the genes that were originally found in the nematodes have their counterpart in mammals: ced-3 corresponds to the caspase-3like caspases; ced-4 corresponds to Apaf-1, and the regulator ced-9, which can turn off or turn on apoptosis, corresponds to a number of inhibitors and promoters such as $B c l-2$ and $B a x$, respectively (29). In mammalian cells, several death receptors have been identified and the intracellular adaptors that provide a signal to the first-level caspases have been delineated. Molecules with similar functions have not yet been identified in the nematodes. It appears that the apoptotic pathway is much more complex in mammalian cells, but most of the events are similar and utilize conserved mechanisms to turn over cells in both nematodes and humans. Table 1 shows some of the identified molecules in this pathway in humans and nematodes.

The endpoint in the apoptotic pathway is a characteristic cleavage of chromatin at internucleosomal sites. The unique caspase-activated DNase, CAD, and its inhibitor, ICAD, have been identified. The ICAD is cleaved by the caspase-3releasing $C A D$, which is responsible for the characteristic cleavage at the end stage of apoptosis (30). Recently it has been demonstrated that apoptosis can be very important in several disease processes. An enhancement of the apoptotic mechanism seems to occur in thyroiditis, ulcerative colitis, and Wilson's disease. Defects in the apoptotic pathway might be encountered in autoimmune diseases and in some proliferative diseases, including leukemia in the lymphatic system. Apoptosis is a very well-controlled mechanism for cell turnover and for specific killing of cells during development and differentiation; therefore, it must be under very exact genetic control. When the control disappears, an accumulation of unwanted cells or cell products may occur, leading to human diseases.

\section{Reversible or Irreversible Exit from the Cell Cycle}

Most of the identified growth arrest genes seem to operate at the checkpoints in the cell cycle, preferably at the Gl/S border fairly late during the Gl stage. Most cells that reversibly or irreversibly exit from the cell cycle are probably exiting close to the G0 arrest stage, which is closer to mitosis in the Gl. The only growth- 
arresting protein found accumulating close to the G0 quiescent state is pl30 in the Rb family (31). It may therefore be of importance in controlling gene transcription in quiescent and differentiating cells, probably by repressing a special subset of E2F-responsive genes (30). Likewise, one of the CDK kinase inhibitors, $p 27^{K i p 1}$, appears to be very important in establishing the quiescent cell state. When an antisense of this gene is ectopically expressed, the cells cannot respond with quiescence either to serum depletion or by contact inhibition (32). Although $p 27$ can inhibit the CDKs associated with cyclin D late in $\mathrm{Gl}$, it might also inhibit cyclin $\mathrm{B}$ kinases that are close to mitosis in the Gl phase.

Some recent data based on studies on Drosophila and mammalian cells seem to indicate, however, that there might be a whole new family of growth arrest genes involved in the quiescent arrest. When the cells ultimately differentiate, it appears in some systems that additional signaling subsequent to growth arrest is required to take the cells into the postmitotic stage. This applies for both adipocyte and myogenic differentiation $(33,34)$. In the former case, a corticosteroid hormone, dexamethasone, was required to establish the postmitotic state of adipocyte development. The addition of dexamethasone led to down-regulation of some of the growth arrest-specific genes that are characteristic of reversible growth arrest close to G0 state. Furthermore, a single transcription factor is required for stationary phase viability in fission yeast (35), which should be compared with the zinc finger protein (APM-1) recently identified at the site of papilloma virus integration, for APM-1 can also cause growth arrest (19). Once the irreversible postmitotic stage has been achieved in the differentiating cells, such as muscle cells, adipocytes, red blood cells, and perhaps the neuronal cells, irreversibility is established. New cells must then be recruited from a stem-cell population that ideally should not replicate in the human body but only be induced to grow at the time of a requirement for replenishment of new cells in a specific pathway. In fact, the induction of stemcell growth might be a condition that truly mimics the growth induction pathway studied with specific oncogenes, encompassing growth factors, growth factor receptors, signal transduction molecules, and nuclear transcription. We obviously have a very long way to go toward understanding cell cycle exit involving either reversible or irreversible growth arrest. 


\section{Conclusions}

This overview has attempted to point to a deficiency in our accumulated knowledge about the control of the cell cycle exit occurring during development, differentiation, and growth arrest. The main reason for the lack of accumulated data is that we have focused on the induction pathway in cell growth and only recently identified some of the molecular players in checkpoint arrest before transition into the $S$ phase. At this stage, the cell must control radiation damage and DNA stability before it can transverse the border. Most of the growth arrest in the human body probably occurs earlier in the Gl state corresponding to the quiescent state (G0), which also precedes some of the differentiation pathways. A much more elaborate approach must therefore be applied to identify the true growth inhibitors in the quiescent state and the interplay that keeps the cells from escaping this control, causing cancer or other diseases. The apoptosis pathway delineated during the last 10 years has clearly shown that apoptosis might occur at the level of the Gl/S checkpoint but not necessarily in the G0 quiescent state prevailing in the organs in the body. Although apoptosis appears to be an important cell turnover mechanism, we must enhance the screen for genes controlling the expression in truly quiescent cells both in vivo and in vitro.

\section{References}

1. Bird AP. (1995) Gene number, noise reduction and biological complexity. Trends Genet. 11: 94100.

2. Loo S, Rine J. (1995) Silencing and heritable domains of gene expression. Annu. Rev. Cell Biol. Dev. 11: 519-548.

3. Rivier D, Rine J. (1992) Silencing: The establishment and inheritance of stable, repressed transcription states. Curr. Opin. Genet. Dev. 2: 286-292.

4. Reifsnyder C, Lowell J, Clarke A, Pillus L. (1996) Yeast $S A S$ silencing genes and human genes associated with AML and HIV-1 Tat interactions are homologous with acetyltransferases. Nat. Genet. 14: 42-49.

5. Borrow J, Stanton VP, Jr., Andresen JM, Becher R, Behm FG, Chaganti RSK, Civin CI, Disteche C, Dubé I, Frischauf AM, Horsman D, Mitelman F, Volinia S, Watmore AE, Housman DE. (1996) The translocation $t(8 ; 16)(\mathrm{pl} 1 ; \mathrm{pl})$ of acute myeloid leukaemia fuses a putative acetyltransferase to the CREB-binding protein. Nat. Genet. 14: 33-41.

6. Eckner R, Ewen ME, Newsome D, Gerdes M, DeCaprio JA, Lawrence JB, Livingston DM. (1994)
Molecular cloning and functional analysis of the adenoviral ElA-associated $300 \mathrm{kD}$ protein (p300) reveals a protein with properties of a transcriptional adaptor. Genes Dev. 8: 869-884.

7. Yang X-J, Ogryzko VV, Nishikawa J, Howard BH, Nakatani Y. (1996) A p300/CBP-associated factor that competes with the adenoviral oncoprotein E1A. Nature 382: 319-324.

8. Petrij F, Giles RH, Dauwerse HG, Saris JJ, Hennekam RCM, Masuno M, Tommerup N, van Ommen G-JB, Goodman RH, Peters DJM, Breuning MH. (1995) Rubinstein-Taybi syndrome caused by mutations in the transcriptional co-activator CBP. $\mathrm{Na}$ ture 376: 348-351.

9. Cory S, Adams J. (1988) Transgenic mice and oncogenesis. Annu. Rev. Immunol. 6: 25-48.

10. Hurlin PJ, Quéva C, Eisenman RN. (1997) Mnt, a novel Max-interacting protein is coexpressed with Myc in proliferating cells and mediates repression at Myc binding sites. Genes Dev. 11: 44-58.

11. Laherty CD, Yang W-M, Sun J-M, Davie JR, Seto E, Eisenman RN. (1997) Histone deacetylases associated with the mSin 3 corepressor mediate Mad transcriptional repression. Cell 89: 349-356.

12. Lee J-S, Galvin KM, See RH, Eckner R, Livingston D, Moran E, Shi Y. (1995) Relief of YYI transcriptional repression by adenovirus ElA is mediated by ElA-associated protein p300. Genes Dev. 9: 1188-1198.

13. Peverali FA, Ramqvist T, Saffrich R, Pepperkok R, Barone MV, Philipson L. (1994) Regulation of $G_{1}$ progression by E2A and Id helix-loop-helix proteins. $E M B O$ J. 13: 4291-4301.

14. Levine AJ. (1997) p53, the cellular gatekeeper for growth and division. Cell 88: 323-331.

15. Rowan S, Ludwig RL, Haupt Y, Bates S, Lu X, Oren M, Vousden KH. (1996) Specific loss of apoptotic but not cell-cycle arrest function in a human tumor derived p53 mutant. EMBO J. 15: 827838.

16. Ruaro EM, Collavin L, Del Sal G, Haffner R, Oren M, Levine AJ, Schneider C. (1997) A proline-rich motif in p53 is required for transactivation-independent growth arrest as induced by Gasl. Proc. Natl. Acad. Sci. U.S.A. 94: 4675-4680.

17. Garkavtsev I, Grigorian IA, Ossovskaya VS, Chernov MV, Chumakov PM, Gudkov AV. (1998) The candidate tumour suppressor $\mathrm{p} 33^{I N G 1}$ cooperates with p53 in cell growth control. Nature 391: 295 298.

18. Wechsler-Reya RJ, Elliott KJ, Prendergast GC. (1998) A role for the putative tumor suppressor Binl in muscle cell differentiation. Mol. Cell. Biol. 18: $566-575$.

19. Reuter S, Bartelmann M, Vogt M, Geisen C, Napierski I, Kahn T, Delius H, Lichter P, Weitz S, Korn B, Schwarz E. (1998) $A P M-1$, a novel human gene, identified by aberrant co-transcription with papillomavirus oncogenes in a cervical carcinoma cell line, encodes a $\mathrm{BTB} / \mathrm{POZ}$-zinc finger protein 
with growth inhibitory activity. EMBO J. 17: 215222.

20. Lee TC, Li L, Philipson L, Ziff EB. (1997) Myc represses transcription of the growth arrest gene gasl. Proc. Natl. Acad. Sci. U.S.A. 94: 12886-12891.

21. Hall M, Peters G. (1996) Genetic alterations of cyclins, cyclin-dependent kinases, and cdk inhibitors in human cancer. Adv. Cancer Res. 68: 67-108.

22. Hainaut P, Soussi T, Shomer B, Hollstein M, Greenblatt M, Hovig E, Harris CC, Montesano R. (1997) Database of p53 gene somatic mutations in human tumors and cell lines: Updated compilation and future prospects. Nucl. Acids Res. 25: 151157.

23. Serrano M, Lee H-W, Chin L, Cordon-Cardo C, Beach D, DePinho RA. (1996) Role of the INK4a locus in tumor suppression and cell mortality. Cell 85: 27-37.

24. Kamijo T, Zindy F, Roussel MF, Quelle DE, Downing JR, Ashmun RA, Grosveld G, Sherr CJ. (1997) Tumor suppression at the mouse INK4a locus mediated by the alternative reading frame product p19 ${ }^{A R F}$. Cell 91: 649-659.

25. Deng C, Zhang P, Harper JW, Elledge SJ, Leder P. (1995) Mice lacking $\mathrm{p} 21^{C I P 1 / W A F I}$ undergo normal development, but are defective in Gl checkpoint control. Cell 82: 675-684.

26. Niculescu AB, III, Chen $X$, Smeets $M$, Hengst L, Prives C, Reed SI. (1998) Effects of p2 $1^{\text {Cip 1/Wafl }}$ at both the $G_{1} / S$ and the $G_{2} / M$ cell cycle transitions: $\mathrm{pRb}$ is a critical determinant in blocking DNA replication and in preventing endoreduplication. Mol. Cell. Biol. 18: 629-643.

27. Dulic V, Stein GH, Far DF, Reed SI. (1998) Nuclear accumulation of $\mathrm{p} 21^{C i p 1}$ at the onset of mitosis: $\mathrm{A}$ role at the $\mathrm{G}_{2} / \mathrm{M}$-phase transition. Mol. Cell. Biol. 18: $546-557$.
28. Hengartner MO. (1996) Programmed cell death in invertebrates. Curr. Opin. Genet. Dev. 6: 34-38.

29. Peter ME, Heufelder AE, Hengartner MO. (1997) Advances in apoptosis research. Proc. Natl. Acad. Sci. U.S.A. 94: 12736-12737.

30. Enarl M, Sakahira H, Yokoyama H, Okawa K, Iwamatsu A, Nagata S. (1998) A caspase-activated DNase that degrades DNA during apoptosis, and its inhibitor ICAD. Nature 391: 43-50.

31. Mayol X, Grana X. (1998) The pl 30 pocket protein: Keeping order at cell cycle exit/re-entrance transitions. Front. Biosci. 3: D11-D24.

32. Rivard N, L'Allemain G, Bartek J, Pouyssegur J. (1996) Abrogation of p27Kipl by cDNA antisense suppresses quiescence (G0 state) in fibroblasts. J. Biol. Chem. 271: 18337-18341.

33. Shugart EC, Umek RM. (1997) Dexamethasone signaling is required to establish the postmitotic state of adipocyte development. Cell Growth Differ. 8: 1091-1098.

34. Walsh K, Perlman H. (1997) Cell cycle exit upon myogenic differentiation. Curr. Opin. Genet. Dev. 7: 597-602.

35. Hao Z, Furunobu A, Nagata A, Okayama H. (1997) A zinc finger protein required for stationary phase viability in fission yeast. J. Cell. Sci. 110: 2557-2566.

36. Kurokawa R, Kalafus D, Ogliastro M-H., Kioussi C, Xu L, Torchia J, Rosenfeld MG, Glass CK. (1998) Differential use of CREB binding proteincoactivator complexes. Science 279: 700-703.

37. Roth SY. (1996) Something about silencing. Nat. Genet. 14: 3-4.

38. Haber DA. (1997) Splicing into senescence. Cell 91: 555-558. 